\title{
SOCIETY PRIZES AND AWARDS
}

\section{Canadian Neurological Society}

\section{FRANCIS MCNAUGHTON MEMORIAL PRIZE and ANDRÉ BARBEAU MEMORIAL PRIZE}

The Canadian Neurological Society invites submissions for its two prizes: the Francis McNaughton Memorial Prize for clinical research and the André Barbeau Memorial Prize for basic research. The rules governing these prizes are listed below.

1. The Francis McNaughton and André Barbeau Memorial Prizes, designed to encourage Neurology Trainees to undertake research projects, are awarded for the best submitted papers based on work done during the Neurology residency or in post-residency training. The contestants need not be the sole authors but should have been primarily responsible for the work to be presented.

2. Junior members of the Canadian Neurological Society and Active Members within two years of obtaining their certification are eligible for these awards.

3. The winning papers in each category will be presented at the annual meeting of the Canadian Congress of Neurological Sciences.

4. Each prize will consist of an inscribed scroll and an honorarium of $\$ 1,000.00$ and registration to the annual meeting of the Canadian Congress of Neurological Sciences.

5. The President of the Canadian Neurological Society and two other Society members chosen by the President twill serve as the Prize Essay Committee. If the Committee finds none of the submissions acceptable, no awards will be presented.

6. Full papers prepared in a standard format, such as that prescribed by the Canadian Journal of Neurological Sciences, are to be submitted in triplicate to the President of the Canadian Neurological Society:

Dr. C.W. McCormick

c/o The Canadian Congress of Neurological Sciences

Suite 810, 906 - 12 Avenue SW, Calgary, Alberta, T2R IK7

7. The deadline for submission is December 31, 1993.

8. When considering the submission of their papers for publication, contestants are encouraged to submit them first to the Canadian Journal of Neurological Sciences.

9. The McNaughton and Barbeau prize competitions are separate from the Abstract competition for presentation at the Canadian Congress of Neurological Sciences. If contestants wish to have their work considered for the general program of the Canadian Congress of Neurological Sciences, a separate abstract should be submitted to the Program Committee on an official Abstract form. However, if the winning papers have also been submitted to the Canadian Congress of Neurological Sciences, the prize presentation shall take precedence.

10. Authors must sign a statement indicating that the paper has not been presented at any other meeting or previously published (presentation at residents/fellows research symposium excluded).

\section{The Royal College of Physicians and Surgeons of Canada with the co-operation of the Canadian Neurosurgical Society}

\section{K.G. McKENZIE MEMORIAL PRIZE AND AWARD}

\section{A. The McKenzie Prize for Basic Neurosciences Research and the McKenzie Prize for Clinical Neuroscience Research}

There will be one citation and prize of $\$ 1,000.00$ in each of the Basic Neuroscience and Clinical Neuroscience categories for the best manuscripts submitted to the McKenzie Award Committee of the Canadian Neurosurgical Society, by a neurosurgical resident, in which he or she is the principal author. The recipients will have their expenses, including air fare, hotel accommodation and registration fees, paid for as part of the Prizes. A second prize of $\$ 500.00$ may also be awarded in each category.

\section{Conditions Governing the Prize}

1. Eligible recipients must be neurosurgical residents registered in a Canadian Resident Training Program. A letter from the Chairman of the Program in which the resident is training should accompany the submission. The letter should state that the work was done by a Neurosurgical Resident and was principally the work of the resident.

2. The original manuscript plus six copies must be submitted to the Chairman of the Awards committee by the stated deadline date. A covering letter from the resident should state the category of the Prize being sought.

3. The manuscript must be typed double-spaced on $81 / 2$ by 11 inch paper with one inch margins on all sides.

4. The manuscript shall generally consist of the following: title page, a single page abstract of not more that 200 words, the text of the manuscript, references, tables, figures and legends. There must be five original photographs of all figures. The references should be cited in the manner used by the Canadian Journal of Neurological Sciences. The text of the manuscript shall not exceed 25 pages in length. Manuscripts not conforming with these regulations will be ineligible. The manuscripts must not have been previously published.

5. Authors must sign a statement indicating that the paper has not been presented at any other meeting or previously published (presentation at residents/fellows research symposium excluded). 


\title{
B. The McKenzie Training or Research Award
}

A grant will be awarded to support specific training or research which may include travel. However, travel to regularly scheduled neurosurgical meetings is excluded. The applicant must be resident in training in a Canadian Neurosurgical Training Program, or if formal training is completed, within two years of having received certification for Fellowship in neurosurgery. The amount to be awarded will be up to $\$ 2,000.00$.

\section{Conditions Governing the Award}

Applicants should forward a comprehensive letter to the Chairman of the Award Committee by the stated deadline date. The application must include the following:

1. A clear description of the training or research which is contemplated, and its purpose, maximum of two pages.

2. A description of other funds available to the applicant; consideration will be given to need.

3. A detailed, proposed budget.

4. A current curriculum vitae of the applicant.

5. Supporting letters from the applicant's current program director and proposed supervisor of the training or research.

6. Authors must sign a statement indicating that the paper has not been presented at any other meeting or previously published (presentation at residents/fellows research symposium excluded).

The deadline for the Prize and Award for 1994 is December 31, 1993. Applicants for the Prize or Award should send their submissions to:

\author{
Dr. C.H. Tator, Chairman \\ K.G. McKenzie Memorial Awards Committee \\ Division of Neurosurgery \\ Toronto Western Division, Toronto Hospital \\ 399 Bathurst St, Mch 2-435, Toronto, Ontario M5T 2S8
}

\section{Canadian Society of Clinical Neurophysiologists}

\section{THE HERBERT JASPER PRIZE}

The Herbert Jasper Prize is awarded annually for the best submitted paper in clinical or basic neurophysiology by a resident or fellow in training. Others who are within three years of receiving a doctorate or fellowship are also eligible.

The prize consists of an honorarium of $\$ 250.00$ and economy air fare to the annual meeting of the Canadian Congress of Neurological Sciences where the winning paper will be presented.

Full papers prepared in the standard format of the Canadian Journal of Neurological Sciences should be submitted in triplicate and consist of a report of the research project findings and relevant related material.

Authors must sign a statement indicating that the paper has not been presented at any other meeting or previously published (presentation at residents/fellows research symposium excluded). The deadline for submission is December 31, 1993. Applications should be submitted to:

Dr. M. Jones

c/o The Canadian Congress of Neurological Sciences

Suite 810,906 - 12th Avenue SW, Calgary, Alberta T2R 1K7

If contestants wish to have their work considered for the general program of the meeting of the Canadian Congress of Neurological Sciences, a separate abstract should be submitted to the Program Committee on the official Abstract form. However, if the winning paper has been submitted to the Canadian Congress of Neurological Sciences, the prize presentation will take preference.

\section{The Canadian Association for Child Neurology}

\section{THE PRESIDENT'S PRIZE}

The President's Prize is awarded annually for the best paper in pediatric neuroscience by a resident or fellow in training. The prize consists of a $\$ 500.00$ honorarium and a commemorative scroll. The winning paper will be presented at the annual meeting of the Canadian Congress of Neurological Sciences. Full papers prepared in the standard format of the Canadian Journal of Neurological Sciences should be submitted in triplicate to:

Dr. D.L. Keene

c/o The Canadian Congress of Neurological Sciences

Suite 810,906 - 12th Avenue SW, Calgary, Alberta T2R 1K7

If the committee finds none of the submissions acceptable, the award will not be presented. Authors must sign a statement indicating that the paper has not been presented at any other meeting or previously published (presented at residents/fellows research symposium excluded).

If contestants wish to have their work considered for the general program of the annual meeting of the Canadian Congress of Neurological Sciences, a separate abstract should be submitted to the Program Committee on the official abstract form. If the winning paper has been submitted to the Canadian Congress of Neurological Sciences, the prize presentation will take preference.

Deadline for receipt of submission is December 31, 1993. 